\title{
How a Small Teaching Center Made a Big Impact During the Pandemic Crises
}

\author{
J. A. Carter, Bradford Mallory, Brenda Refaei, \\ and Ruth Benander
}

\section{Abstract}

For many faculty developers, 2020's challenges changed our approach to our work. We found that by expanding our networks and relying on our collaborative spirit, we were able to adapt quickly and effectively to changing events. Each member of our four-person Learning + Teaching Center (LTC) team brings expertise and skills for faculty development. We employ a holistic approach to faculty development that not only provides programming for teaching improvement but also addresses the social and emotional needs of faculty and staff. The challenges of 2020 forced faculty and staff to work remotely, which necessitated more programming in how to use online technology. In addition, many faculty and staff were deeply troubled by the racial inequities brought to nationwide attention during the spring and summer. During these crises, we moved all of our programming online. We found that participation numbers increased online, but social interaction decreased. We recommend faculty developers continue offering online workshops in addition to in-person opportunities, work with faculty to adapt to new teaching opportunities, build up networks to bring in internal and external experts, and adopt an ethic of care for others and oneself.

Keywords: COVID-19, racial equity, online learning, holistic faculty development 
As our open-access, regional campus of roughly 6,000 students shifted to remote learning in response to the COVID-19 pandemic, our Learning + Teaching Center (LTC) staff unsurprisingly faced many challenges. Our Carnegie R1 university has a Center for Excellence in Teaching and Learning and a Faculty Enrichment Center with a fulltime complement of staff with whom we collaborate, but our smaller campus center serves specifically our regional campus with four faculty members with release time. Like other universities, our first challenge was with technology. Transitioning to remote learning required many faculty to learn new technologies they never expected to need. For many of our faculty, the move to online learning was made more difficult because Spring Semester 2020 was when the university shifted to the Canvas learning management system (LMS). Our institution had used Blackboard for more than 20 years before the transition to Canvas. Thus, in addition to learning how to use our web conferencing and video creation tools, our faculty were in the early stages of a full LMS transition.

This use of new technology was linked to our second challenge: to identify creative means for adapting active learning pedagogies into online environments. As a college that features small class sizes and prioritizes interactivity in our classrooms, it was important that we find ways to cultivate interactivity online. This effort generated a third challenge-creating and maintaining equitable spaces-as faculty, staff, and students were now being asked to essentially invite others into their homes in the virtual environment using technologies difficult for all to access. Additionally, many faculty and staff were deeply troubled by the racial inequities brought to nationwide attention, which brought a sense of urgency to issues of equity and inclusion.

Finally, our fourth challenge involved caring for our increasingly stressed community. At the LTC, we offer holistic programming for faculty and staff development that acknowledges the multifaceted nature of working in higher education, as Sugrue et al. (2018) suggest, "recognising the person who is the academic, beyond their disciplinary identity" (p. 8). For us, this has meant a commitment to 
caring for the mind and body in the stressful academic environment. Obviously, this stress was exacerbated by the pandemic and broader social climate.

In this article, we start by discussing each of the four challenges we faced and how we responded. We then address how we assessed our success. Finally, we conclude with takeaways and recommendations for future faculty development.

\section{Challenges and Responses}

\section{Technology Changes}

During Fall Semester 2019, the college LTC offered a robust array of training opportunities to assist the transition to Canvas, but Spring Semester 2020 was the first time all instructors at the college were required to use the new LMS. Many of our faculty had limited experience creating a course structure using Canvas and designing effective assignments for online submission with rubrics. Even basic tasks like creating a column in the Canvas Gradebook were unknown to many faculty who previously only taught in face-to-face learning environments. Learning to teach online at the same time as learning to use a new LMS intensified their stress.

In response to the challenge of the technological changes, we created more online workshops and seminar series. Most of these workshops offered a synchronous online event and an asynchronous recording for those who could not attend or wanted to revisit various sections. We also offered a nine-module, self-paced online design "course" for faculty. Faculty could use the modules to help build their course stepby-step and receive feedback on their progress after each module. More than 120 faculty engaged in the course material in some way, and 43 submitted work for review. However, just 19 completed the course. Instead of working through the modules, we found that faculty's desire for personal consultations increased. It seemed that our 
workshops on course redesign, for example, were treated as introductions to the content, and then in surveys and in practice, faculty preferred a personal consultation for application of those ideas to their own courses. This created a high demand for personal attention at both our college and, anecdotally, across our university.

\section{Adapting Pedagogies to Online Teaching}

In addition to assisting with technology challenges, we helped faculty adapt interactive teaching styles to the online environment. Our college is structured for small class sizes, emphasizing one-on-one interactions between faculty and students with an average studentto-professor ratio of 18:1. Thus, most of our faculty teach using an active learning approach. This pedagogy was not easily adapted to the online environment for faculty who had only facilitated in-person group work. Therefore, the center focused on identifying technologies and strategies that make online learning more interactive. This focus included workshops on how to create breakout rooms in web conferencing systems, discussions of effective use of those breakout rooms, and using the chat function to keep students engaged. We tried to model this approach in our own workshops, by using the chat to take and answer questions throughout the sessions and using breakout rooms for small group discussions in some workshops. We frequently asked participants about their experiences, which encouraged interaction. This engagement allowed us to identify and target the unique needs of different disciplines and staff offices. Modeling this interaction in our workshops also illustrated techniques instructors could use in their courses.

\section{Creating and Maintaining Equitable Spaces}

Addressing online teaching challenges includes how to create and maintain equitable online learning spaces. Equity and inclusion is emphasized in our college mission and the LTC's objectives. As an open- 
access college, and the university's most diverse college, we are committed to addressing the needs of students from a wide array of backgrounds and experiences. Moving online, the need to create accessible courses and equitable remote spaces meant facing the digital divide head-on and reorganizing university resources to address the physical and knowledge-based technological inhibitors faced by our students, faculty, and staff. It also meant rethinking expectations, such as consistent synchronous sessions, and access to resources, such as webcams and internet with strong bandwidth. So, at the same time we were identifying creative methods for online interaction, we knew that the best methods might elude the students most in need due to technology access issues. Additionally, our support staff were concerned about how to assist struggling students.

Our response to the challenges of creating equitable, inclusive online experiences was supported by our institutional ethos. Our college has a deep commitment to access, equity, and inclusion, and the racial protests in 2020 gave even greater urgency to develop opportunities to challenge systemic racism within our college. We recognized that faculty, staff, and students were deeply affected by current events and needed opportunities to process what was happening. In addressing these needs, we followed Wright et al.'s (2018) suggestions of finding means for leveraging connections and collaborating with others. We were fortunate that the university's Office of the Provost conducted listening sessions with faculty and staff. At our college, our program manager of inclusion and involvement and our coordinator of multicultural affairs conducted similar listening sessions with students. The LTC then invited them to present what they learned from students, so faculty and staff could be more informed about student experiences. We also collaborated with them and the Diversity, Equity, and Inclusion Committee to create a series of transformational equity workshops. These monthly workshops were held during the academic year, and participants who attended most of the events received a certificate. This workshop series was a good opportunity to open dialogue about important equity and inclusion concepts, such as implicit bias. 


\section{Caring for Our Community}

Our final challenge has been in creating community for faculty/staff in a virtual world. Our physical LTC space used to be a vibrant area for congregation. Our face-to-face workshops included snacks, beverages, and consistent interaction. We used the wall-to-wall whiteboards to brainstorm and share ideas. We used our circular tables to optimize small group work and encourage discussion. When center activities moved online, we felt like we lost connection with one another. With so much change and loss hitting us at once, our faculty, staff, and students were understandably overwhelmed. As Jacobson and Cole (2020) noted in their survey of faculty about motivation to change, they found faculty regarded change as effortful, costly, and of limited benefit. This skepticism of change and feeling of loss created a great deal of tension in our efforts to provide appropriate support.

In our response to the challenge of caring for our community, we needed to address the added stress and anxiety created by all these challenges. We are fortunate to have a licensed yoga instructor who provided guided accessible instruction titled "Yoga in Your Work Clothes." On campus, approximately 7-10 people attended sessions. After moving online, 20-30 people attended. In faculty and staff surveys, participants noted that these yoga sessions were extremely helpful in managing stress from working remotely. However, like other ventures online, interactivity was impacted. For instance, in-person sessions included personalized support specific to an individual's needs. The online sessions are not individualized, although participants can pose questions in the chat for after the session or stay to ask a question at the end of a session.

\section{Assessment of Our Programming}

We assessed our success in shifting from in-person events to online events through the number of participants and the amount of interac- 
Table 1. Comparison of Center Activities Before and During the Pandemic Response

\begin{tabular}{|c|c|c|}
\hline Before & Pandemic response & Change effect \\
\hline $\begin{array}{l}\text { Online Instructor Train- } \\
\text { ing: included due dates, the- } \\
\text { ory, isolated exercises, peer } \\
\text { review }\end{array}$ & $\begin{array}{l}\text { Online Instructor Training: self- } \\
\text { paced, personal course } \\
\text { development, self-review }\end{array}$ & $\begin{array}{l}\text { Before pandemic: } 10 \text { attendees } \\
\text { per semester } \\
\text { During pandemic: } 124 \text { fac- } \\
\text { ulty members accessed the mod- } \\
\text { ules, } 43 \text { submitted work for feed- } \\
\text { back, } 19 \text { completed all modules }\end{array}$ \\
\hline $\begin{array}{l}\text { Single-event face-to-face (F2F) } \\
\text { workshops }\end{array}$ & $\begin{array}{l}\text { Two focused series: online } \\
\text { facilitation (four days) and } \\
\text { online tools (four days); } \\
\text { recorded with links made } \\
\text { available }\end{array}$ & $\begin{array}{l}\text { F2F workshops: } 10-15 \text { attendees } \\
\text { Pandemic Online focused } \\
\text { series: } 50-70 \text { attendees per ses- } \\
\text { sion, with an average of } 30 \text { video } \\
\text { views afterward }\end{array}$ \\
\hline $\begin{array}{l}\text { Personal consultations tacitly } \\
\text { available }\end{array}$ & $\begin{array}{l}\text { Personal consultations actively } \\
\text { promoted }\end{array}$ & $\begin{array}{l}\text { Increased requests for personal } \\
\text { help and support sessions } \\
\text { through Webex and email }\end{array}$ \\
\hline $\begin{array}{l}\text { No central location for } \\
\text { resources }\end{array}$ & $\begin{array}{l}\text { Online Teaching Community } \\
\text { Canvas site created; weekly } \\
\text { emails with links to resources }\end{array}$ & $\begin{array}{l}80 \text { instructors are in the Online } \\
\text { Teaching Community, of whom } \\
58 \text { are active with average view- } \\
\text { ing time of } 30-60 \text { minutes (low, } \\
10 \text { minutes; high, } 2 \text { hours) }\end{array}$ \\
\hline $\begin{array}{l}\text { Faculty Learning Communities } \\
\text { (FLC), F2F }\end{array}$ & $\begin{array}{l}\text { Faculty Learning } \\
\text { Communities online }\end{array}$ & Participation did not change \\
\hline $\begin{array}{l}\text { F2F Cultural Diversity FLC ran } \\
\text { for } 2 \text { years: } 30 \text { attendees } \\
\text { F2F Diversity and Inclusion } \\
\text { Learning Circle ran for } 2 \text { years } \\
\text { with special program at writing } \\
\text { retreat: } 12 \text { attendees }\end{array}$ & $\begin{array}{l}\text { Online Transformational Teach- } \\
\text { ing Series ( } 4 \text { sessions, total of } \\
63 \text { attendees) }\end{array}$ & $\begin{array}{l}\text { Participation increased; we have } \\
\text { always been committed to this } \\
\text { issue; because of the heightened } \\
\text { awareness of social inequality, } \\
\text { more faculty and staff are eager } \\
\text { to participate in programming }\end{array}$ \\
\hline $\begin{array}{l}\text { Yoga in Your Work Clothes } \\
\text { F2F sessions: } 7-10 \text { attendees; } \\
\text { personalized interaction }\end{array}$ & $\begin{array}{l}\text { Yoga in Your Work Clothes } \\
\text { online sessions: } 20-30 \text { attend- } \\
\text { ees; questions posed in chat or } \\
\text { after the session }\end{array}$ & $\begin{array}{l}\text { Greater attendance online from } \\
\text { across the university but no } \\
\text { interaction }\end{array}$ \\
\hline
\end{tabular}

tion among participants. When the LTC activities went wholly online, we were successful in that our attendance increased dramatically. However, we were less successful in maintaining strong interactions. In-person workshops included more interactive learning with fewer participants, whereas the change to online workshops included more participants but less group interaction. Trust et al. (2017) in their study of faculty participation in online professional networks noted, "The low barriers to 
participation that exist with many social media tools create both opportunities and challenges for higher education faculty and staff" (p. 8). Indeed, the ease of logging in to online workshops from home seemed to support greater attendance. However, fostering substantive interaction has been challenging when it is easy to turn off the camera and the microphone in an online group of 60 people. Participants seem to prefer to listen to the online workshops and then schedule personal consultations through video chats or email with the LTC staff. Thus, the overall change involves more touchpoints, less group interaction, and more personal consultations. These numbers indicate that we are more successful at reaching a broader audience, but it seems to be a community of shallower connection.

In addition to noting these changes in our service to our colleagues, we determined that our LTC team sustained one another through the increased demands for instructor support by maintaining good team communication. Our center exemplifies Beach et al.'s (2016) "Age of the Network" in professional development. We cultivated a team approach so no one needed to accomplish center tasks alone. Following a holistic orientation to supporting personal growth, we believe that we need to invest in deepening the relationships among the developers as well as the members of our community. Due to the cancellation of conferences, we realized that conference attendance for members of our center staff was an important component of building camaraderie as well as cultivating content knowledge and professional networking. Attending conferences is a team building event that fosters the resiliency of our team's response to crises. For example, attending POD is professional development outside our disciplinary work that has served to strengthen our team as well as our professional expertise. 


\section{Takeaways}

\section{Technology: Online Learning Expands}

We recommend a mixture of online and in-person programming postpandemic. Although the online environment seemed to lack the personal connection we experience when face-to-face, we did see a significant increase in the number of participants. We believe this was due to convenience. In a post-pandemic world, the dual approach could use the online component to introduce content, and the inperson interaction can be used to develop depth around key components. We suggest recording most programs for future review; however, we recommend that programs exploring sensitive or personal topics not be recorded.

\section{New Pedagogies: Do What We Can and Not Worry About What We Cannot Do}

Instructors who value active learning obsess over things like, "Did I do enough? How can I help everyone?" In challenging times, instructors need to take a cue from mindfulness practices by being present, in the moment, without judgment. Being "without judgment" is critical since it is easy to fall into the downward spiral of feeling guilty for not doing enough. We recommend that faculty developers help instructors recognize that it is just not feasible to teach as we taught pre-pandemic, nor should we try. Such futile efforts could lead to burnout. Instead, we suggest that faculty developers help instructors streamline activities and distill their curriculum to focus on the essentials of course learning outcomes. 


\section{Equity and Inclusion:}

\section{Include the Whole Community for Equitable Solutions}

For many of our colleagues, the issues of equity and inclusion are not isolated concerns; they are always a present reality. Faculty developers need to look for experts at their institution who can identify and speak to issues of equity and inclusion that can then be addressed throughout all faculty development programming. Many institutions have offices of equity and inclusion with colleagues whose expertise should be drawn upon to create programming that moves the institution toward a more inclusive environment. In addition, developers might work with faculty who research best practices in equity and inclusion to create new programming. Developers should keep up with national and regional challenges in addressing equity and inclusion in higher education but also be aware of challenges specific to their own institution. Once needs for equity and inclusion programming are identified, systems and programs must be developed to address those needs. For example, in our programming, we included institutional data, consultation with student services, and the expertise of the coordinator of multicultural affairs to inform and present throughout the year. Involving colleagues from outside the LTC in the professional development process creates a sense of shared value, increases agency, and fosters camaraderie in furthering the institution's equity and inclusion goals. The pandemic laid bare existing inequalities in society. It is imperative that LTCs continue to promote equity and inclusion in their work in the effort to create a more just society, and this means including all members of the academic community in this work.

\section{Caring for Our Community:}

\section{Offer Personal and Professional Development}

This period has been fraught with the challenges of living under quarantine orders because of the pandemic; addressing issues of social injustice and inequity, economic hardship, and uncertainty; and the 
shifting roles of family members as workers (remote or in person), educators (for virtual learning), and caregivers (for children and family members). This convergence of challenges has caused everyone to be stretched thin. As faculty developers we need to be mindful and provide programs, activities, and opportunities for the professional development of our colleagues who are tired, stressed, and may be struggling personally. We recommend centers take a holistic approach by offering programming that addresses working during a period of remote learning. This could include things from best practices for online pedagogy to how to engage students in online environments. We also recommend providing health and wellness opportunities even after the pandemic. A healthy incorporation of sessions on mindfulness and movement, addressing issues of social justice with our students and colleagues, and on how to effectively teach in online environments is the holistic approach that we believe best supports, encourages, and engages our faculty while addressing feelings of isolation, burnout, and self-doubt.

\section{Recommendation for Faculty Developers: Take Care of Yourself}

It may be cliché, but the advice to put your own oxygen mask on before helping others also applies to our work as faculty developers. Emails, consultations, and trainings have increased to accommodate and alleviate the concerns of faculty in a stressful environment. Grupp and Little (2019) note that successful faculty developers have specific meta-competencies, such as "Timmermans' core ways of knowing and being (2014, p. 310), which include collaborating and building relationships, adopting a scholarly approach, communicating effectively, understanding and adapting to context, and reflection." In our experiences, we found these competencies key to our success in adapting to the needs of the faculty we care for. We found that our team has been invaluable not only for providing resources to move very quickly online 
and holistically support our faculty during this period of remote learning but also as a resource for one another in reflection. Our team provides grounded, safe, supportive, non-judgmental encouragement for each of us to thrive and continue to do the work of professional development. We should not discount the importance of the work that we do as faculty developers. The work can be hard, tedious, and stressful, but it is tremendously important, rewarding, and necessary.

\section{Biographies}

J. A. Carter is an Assistant Professor of Sociology in the Behavioral Science Department at the University of Cincinnati Blue Ash College. She is also the Canvas Leader in the college's Learning + Teaching Center. She has previously been published in the Journal for Research and Practice in College Teaching, the Association for University Regional Campuses of Ohio Journal, and Women in Sports: Breaking Barriers, Facing Obstacles.

Bradford Mallory is an Associate Professor in the Biology Department and the Co-director of the Learning + Teaching Center at the University of Cincinnati Blue Ash College. His focus in the center has been to promote diversity, equity, and inclusion in instruction. He has previously published in the Journal for Research and Practice in College Teaching and the Association for University Regional Campuses of Ohio Journal.

Brenda Refaei is a Professor in the English and Communication Department and the Co-director of the Learning + Teaching Center at the University of Cincinnati Blue Ash College. She has previously published in Teaching English in the Two-Year College, International Journal of ePortfolio, and the Journal for Research and Practice in College Teaching. 
Ruth Benander is a Professor in the English and Communication Department and the Online Quality Design Leader in the Learning + Teaching Center at the University of Cincinnati Blue Ash College. She is also the General Editor of the Journal for Research and Practice in College Teaching and has previously published in The Journal of Faculty Development, International Journal of ePortfolio, and the International Journal for the Scholarship of Teaching and Learning.

\section{References}

Beach, A. L., Sorcinelli, M. D., Austin, A. E., \& Rivard, J. K. (2016). Faculty development in the age of evidence: Current practices, future imperatives. Stylus Publishing.

Grupp, L. L., \& Little, D. (2019). Finding a fulcrum: Positioning ourselves to leverage change. To Improve the Academy, 38(1). https://doi.org/10.3998 /tia.17063888.0038.103

Jacobson, W., \& Cole, R. (2020). Motivations and obstacles influencing faculty engagement in adopting teaching innovations. To Improve the Academy, 39(1). https://doi.org/10.3998/tia.17063888.0039.106

Sugrue, C., Englund, T., Solbrekke, T. D., \& Fossland, T. (2018). Trends in the practices of academic developers: Trajectories of higher education? Studies in Higher Education, 43(12), 2336-2353. https://doi.org/10.1080/0307 5079.2017.1326026

Timmermans, J. A. (2014). Identifying threshold concepts in the careers of educational developers. International Journal for Academic Development, 19(4), 305-317. https://doi.org/10.1080/1360144X.2014.895731

Trust, T., Carpenter, J. P., \& Krutka, D. G. (2017). Moving beyond silos: Professional learning networks in higher education. The Internet and Higher Education, 35, 1-11. https://doi.org/10.1016/j.iheduc.2017.06.001

Wright, M. C., Lohe, D. R., Pinder-Grover, T., \& Ortquist-Ahrens, L. (2018). The Four Rs: Guiding CTLs with responsiveness, relationships, resources, and research. To Improve the Academy, 37(2). https://doi.org/10.3998/tia.170 63888.0037.206

To Improve the Academy • Vol. 39, No. 3 • Spring 2021 
